Jürgen Domes / Marie-Luise Näth

\title{
Geschichte der Volksrepublik China
}

Meyers Forum, Band 5

B.I. Taschenbuchverlag, Mannheim, 1992, 128 S., DM 14,80

In Band 5 der vom Taschenbuchverlag des Hauses Bibliographisches Institut und F.A. Brockhaus AG neu konzipierten Reihe "Meyers Forum" haben die als Chinakenner ausgewiesenen Autoren in dem für die Reihe vorgegebenen Umfang von 128 Seiten eine Geschichte der Volksrepublik China geschrieben, die dem am Thema Interessierten (und das sollten wir alle sein) in konziser, aber gut lesbarer Form eine Fülle zuverlässig recherchierter Fakten bietet. In drei Teilen zu je vier Kapiteln werden A: Die Durchsetzung des Sozialismus (1949-1959); B: Der Sozialismus in der Dauerkrise (1959-1977) und C: Wirtschaftsreformen, Volkserhebungen und die Agonie des Sozialismus (1977-1989) behandelt, wobei in je drei Kapiteln die innere Entwicklung dargestellt, wird, während das jeweils vierte Kapitel außenpolitischen Problemen gewidmet ist, unter denen naturgemäß das Verhältnis zur Sowjetunion dominiert.

$\mathrm{Zu}$ danken ist den Verfassern besonders, daß sie ihre Untersuchungen auf gesicherten Erkenntnissen aufbauen und schon damit der in Deutschland weit verbreiteten Legendenbildung hinsichtlich China ("emanzipatorischer" Charakter des Regimes, gefühlsmäßige Verankerung in der Bevölkerung) entgegenwirken (S. 9). So ist es gut, daran zu erinnern, mit welcher Brutalität die kommunistische Führung in den Anfangsjahren der VR China ihre Macht sichern zu müssen glaubte: In vier der sechs Großregionen Chinas (für die Zahlen vorliegen) kam es 1949/50 zu 1,176 Millionen Todesurteilen und Hinrichtungen, denen in einer zweiten Welle 1951/52 weitere 2 Millionen folgten (S. 13/14). Auch die wirtschaftlichen "Erfolge" des Regimes werden zu Recht relativiert: Zwar hat sich das ProKopf-BSP von 1951 bis 1991 fast versechsfacht, doch stieg es im gleichen Zeitraum in Taiwan um das 81 fache (S. 121)! Was bleibt, ist die erstmals seit Jahrzehnten gelungene Etablierung einer effektiven zentralen Staatsmacht und der Aufstieg Chinas vom Spielball fremder Mächte zur eigenständigen Groß-, wenn schon nicht Weltmacht (S. 14/15, 113115).

Kritisch hinzuweisen ist auf den abrupten Einstieg ins Thema (S. 11/12), der den mit der Geschichte Chinas weniger Vertrauten etwas verwirren dürfte. Auch neigen die Autoren zur monokausalen Erklärung von Vorgängen, die deren Komplexität nicht immer gerecht wird. So ist es sicher zu kurz gegriffen, den chinesisch-sowjetischen Konflikt allein und ohne Bezug auf historische Auseinandersetzungen als doktrinären Streit zwischen den beiderseitigen Herrschaftseliten erklären zu wollen (S. 73). Auch ist es noch keineswegs ausgemacht, ob die "Agonie des sozialistischen Systems" tatsächlich schon begonnen hat (S. 121). Diese Mängel vermögen aber weder den Genuß noch den Nutzen zu mindern, die mit der Lektüre verbunden sind.

Der Verlag hat, das belegt der vorliegende frühe Band, mit der Reihe "Meyers Forum" einen vielversprechenden neuen Weg beschritten. Schon der Blick auf die ersten acht 
Bände dieser Reihe zeigt die Weite des Themenspektrums. Neben der allgemeinen Geschichte (außer dem hier besprochenen Band auch "Das sowjetische Vielvölkerimperium", Bd. 9, "Geschichte der Stadt Berlin", Bd. 6) werden auch Bereiche abgedeckt wie "Die deutsche Frage 1806 bis 1991" (Bd. 1), "Wahlforschung" (Bd. 2), "Soziale Marktwirtschaft" (Bd. 4), "Allgemeine Wirtschaftspolitik" (Bd. 7) und "Radioaktivität" (Bd. 8). Wahrhaft ein begrüßenswert umfangreiches Spektrum, das für die Reihe auch Programm sein soll.

Karl Leuteritz

Werner Pascha

Korea. Eine Wirtschaft zwischen Aufbruch und Umbruch

Meyers Forum, Band 37

B.I. Taschenbuchverlag, Mannheim, 1996, 128 S., DM 16,80

In der seit 1992 erscheinenden Reihe "Meyers Forum" kommen anerkannte Fachleute zu sehr unterschiedlichen Wissensgebieten in allgemeinverständlicher und gut lesbarer Form zu Worte. Zur Wachstumsregion Ostasien liegt nun bereits der vierte Band vor, der sich nach China (Bd. 6) und Japan (Bd. 16, 24) mit dem in Deutschland zu Unrecht of t vernachlässigten, gar nicht so "kleinen" Tiger Korea beschäftigt.

Mit Werner Pascha, der an der Universität Duisburg das Fach Ostasienwirtschaft / Wirtschaftspolitik vertritt, ist hierfür ein besonders qualifizierter Autor gefunden worden. In sechs der zehn prägnant und informativ geschriebenen Kapitel beschreibt und analysiert er den Aufstieg Süd-Koreas vom hoffnungslosen Fall zum erfolgreichen Spätentwickler, vernachlässigt aber nicht die für das Verständnis wichtigen geographischen, geschichtlichen, politischen und sozio-kulturellen Voraussetzungen dieser wirtschaftlichen Erfolgsgeschichte.

Was den wißbegierigen Leser wahrscheinlich irritiert, daß nämlich nur ein kurzes Kapitel (6 Seiten) dem "verlorenen Bruder" Nord-Korea gewidmet ist, überrascht den Ostasienkenner nicht: Der nahezu vollständige Mangel aussagekräftiger Daten macht zuverlässige Aussagen über dieses abgeschottete Land so gut wie unmöglich. Um so bemerkenswerter sind die Bemerkungen Paschas über die im Vergleich zu den Problemen der deutschen Wiedervereinigung erheblich größeren Schwierigkeiten, die der Politik und Wirtschaft SüdKoreas aus einer Wiedervereinigung mit dem Norden erwachsen würden (S. 112/113).

Wesentlich mehr Raum wird den Außenwirtschaftsbeziehungen Süd-Koreas gewidmet (21 Seiten). Neben allgemeinen Problemen wie der noch immer nicht voll überwundenen Tendenz zur Marktabschottung, der Rolle der Direktinvestitionen und des Technologietransfers sowie der Auslandsverschuldung werden hier die Beziehungen zu den Haupthandelspartnern USA (größter Abnehmer) und Japan (größter Lieferant), aber auch zu Deutschland 